\title{
Analysis of National Health Resource Allocation and Policies During the Covid-19 from a Supply and Demand Perspective
}

\author{
Yunqing Luo* \\ Department of Economics, Georgia Institute of Technology, North Ave NW, Atlanta, US \\ luoyunqing1997@163.com
}

\begin{abstract}
This paper discusses the unique health resources allocation and policies during the Covid-19. Through real data collected by different countries and health institutions, we will be able to observe how different countries responded to the pandemic. Through the supply and demand model, we analyze how market and government policies address the problems associated with the short-run gap between supply and demand for health care resources caused by the epidemic. Effective government responses and potential problems for governments in responding to public emergencies are also discussed. We hope to provide a holistic analysis of the situations caused by Covid- 19 in different countries so that we are better prepared for the future.
\end{abstract}

Keywords: law of supply and demand, government regulation, resource allocation

\section{INTRODUCTION}

Covid- 19 attacked the world without any notice in February 2020. The disease soon developed into a pandemic that seem to have no effective vaccine for now. As of June 11, 2020, Covid- 19 had resulted in more than 7 million cases and 408 thousand deaths [1]. COVID- 19 mainly targets people's respiration system and is infected through droplets. People with close contact can be infected easily. There have been cases where people just walked by and others were infected. What's more special, some patients show no symptoms which means they have more time to infect other people. This pandemic stressed health systems around the world in a time of crisis. Every country used different strategies to maximize the utility brought by their limited medical resources: widespread testing, creating more hospital capacities, securing critical equipment, etc. However, results varied. In some countries, despite timely decision-making decisions, the rate of spread of the disease has not been controlled very effectively due to limited availability of medical resources supply. In this paper, we would like to analyze the weaknesses in our current health management systems by discussing the health system's response to the pandemic and the problems it faces.

\section{REVIEW OF THEORIES OF ECONOMIC RESOURCE ALLOCATION AND THEORIES OF SUPPLY AND DEMAND}

\subsection{Resources Allocation}

Allocation of resources is always an issue as the supply is always limited, no matter what product or service it is. Human, on the other hand, have unlimited desire. The limited supply (scarcity) means that the most efficient decision is to maximize the use of limited resources. Thus, manufacturers will make production decisions based on the principle of profit maximization; consumers will make consumption decisions based on the principle of utility maximization; and the government's concern is to maximize social welfare. And because of the society, the scarcity will also create competition: price, lottery, etc. Just like Lionel Robbins defined economics as "the science which studies human behavior as a relationship between ends and scarce means which have alternative uses."

\subsection{Supply and Demand}

When we look at the market from an economic perspective, we typically focus on demand and supply, 
where at equilibrium market prices, both suppliers and consumers maximize profits. The supply and demand model allow economists to see how different variables change the equilibrium price and quantity, which is reflected in the curve. However, when the supply excesses the demand, there is a surplus; when there is more demand than supply, we will have a shortage. In theory, no matter it is surplus or shortage, the market will go back to equilibrium price, but this process takes time. In the real world, however, a perfectly competitive market state is extremely ideal, and there is no single measure of an efficient market state, making government intervention particularly important.

\subsection{Government and Government Intervention}

The government will be able to adjust the market by adding restrictions or giving certain benefit to the producers to reduce the price. The reason we have government intervention is to make sure we have effective resources allocation. Another scenario the government will intervene is monopoly: lack of competition in the market. Even though we now have enough law and regulation to prevent monopoly, certain markets like public utilities will have natural monopolies due to economies of scale and high investment. To make sure the market is robust, government will set up extra regulation, like price capping or nationalization.

It is easy to see that government seems to have different goals with firms and people. For the government, profit and cost are important, but the primary goal is to stabilize the market to achieve Pareto improvements in social welfare. This goal can be separated into multiple small goals like reducing unemployment, inflation, etc. To reach these goals, government will use tools that are unique to government: interest rate, tariff, exchange rate, etc. All of these can be seen as government intervention.

\section{OVERALL IMPACT OF THE PANDEMIC}

\subsection{Background Information}

From March 30 to April 30, mercy- class hospital ship Comfort stationed in New York city to treat noncoronavirus patients. The idea is good, as this reduces cross infection and supply needed treatment for other diseases. However, the treated number is very limited: only 146 cases. Considering the limited resources, this is one of the worst uses of medical resources under the pandemic. As a professional hospital ship, it was designed for floating more than 1,000 beds. Over the one- month period, only one tenth of the expected number are treated. When the ship first arrived, people expected the ship would take some pressure off from local hospitals in NYC. This allocation of resources should help more people than merely 146 people. For the first country having the outburst of Covid-19, China also uses some good strategy to solve the shortage of medical resources. As China is a large country, there are certain areas that have relatively small infected people with more than enough resources. China reallocated some doctors and nurses to serious areas like Wuhan. This reallocation is effective but still not enough to fully satisfy the demand of all people. This method may not be copied directly for other countries due to different policies; the core idea has some good points. Countries can find people who are unemployed due to shutting down of public areas to produce or at least help producing medical supplies: packing and carrying the resources, for people with some experiences in working in the factories, they will also help increasing the production speed. Additional help in hospitals will definitely help more people getting treated or at least receiving some professional advice. This will also control the level of financial pressure in the society, bringing more potential jobs. There is an additional subject to notice, the workers will also need to pay more attention to their own health as working places are also relatively crowded, creating an ideal environment to pass the virus to each other.

\subsection{Analysis of Medical Resources by Country During the Epidemic}

Medical resources are all materials, facilities, personnel and everything else that can be used for providing to provide health care. The amount of medical resources is a critical element to evaluate countries' health systems. People's demand for health is unlimited, while the supply of medical resources is limited, especially under the pandemic. When scientists study the unique features of Covid- 19, people cannot help to notice the reproduction number is higher than previous pandemics like SARS, as a result, the medical resources supply is in an even higher shortage: demand for the product and service exceeds the supply in the market. We can see in Figure I (Shortage in the market): the total demand for medical resources is at Q2, but at price P1, the market only has Q1 number of products. Even though mobile cabin hospitals and hospital ships were used by some countries, the overall hospital data of different countries didn't change a lot. Practicing physicians' numbers also cannot increase significantly overnight. From the data from the world band, Germany may have the highest amount of practicing physicians and hospital beds per 1000 people, but the number is still low. The detailed data is in Table I[2][3]. Given the theoretical contagion curve is a bell curve, we expect more and more cases as the pandemic spreads around the country until reaching the peak point. As confirmed cases worldwide, also backs up the idea that more people were infected [4].

COVID- 19 pandemic has made a huge impact on society. While the governments tried to slow down the 
outbreak, people still had a sharp increase in demand for specific goods like groceries and drugs, especially at the early stage of the pandemic. At the same time, the supply side was actually experiencing troubles, such as face masks and other medical products. The market was unstable. Because of the pandemic, we experienced a lot of restrictions in life which gave some sectors huge blows. When these sectors experienced a large shock, they would bring it down to its related sectors due to chain reactions.

However, due to the unique characters of drugs, the market demand and supply are different from normal products. When we faced a lot of demand of drugs due to the pandemic, a lot of factories experienced troubles of getting raw materials due to the travel restrictions. Some firms can increase the supply by having extra manufacture machines, but this kind of new demand was just short- time increase. The amount of demand tends to drop back to the original level when the pandemic is over. The purchase of new machines may actually result in a financial deficit, which is not the outcome the companies want to see. There were also reduced workforce due to sickness. All these factors created larger shortages of drugs. Another point of the pandemic is there is uncertainty of the most effective drugs. Until now, we are still in experiment phases of the new drugs and vaccines. To find out the best solution, there is need of more experiments which created a larger demand of all the materials. The governments also responded to the situation by temporarily banning the export of drugs to make sure domestic demand is met first, which put some countries which highly rely on importing facing a larger problem. The follow-up policies varied depending on the countries' situations: setting up more factories and hiring unemployed people to increase the supply of the drugs, encouraging other factories modify its production lines into manufacturing medical supplies, etc.

Table I Number of physicians and hospital beds (per 1,000 people) [3][4]

\begin{tabular}{lll}
\hline & Hospital beds & Physicians \\
\hline US & $2.9 / 100$ & $2.6 / 100$ \\
Canada & $2.7 / 100$ & $2.6 / 100$ \\
Germany & $8.3 / 100$ & $4.2 / 100$ \\
China & $4.2 / 100$ & $1.8 / 100$ \\
UK & $2.8 / 100$ & $2.8 / 100$ \\
\hline
\end{tabular}

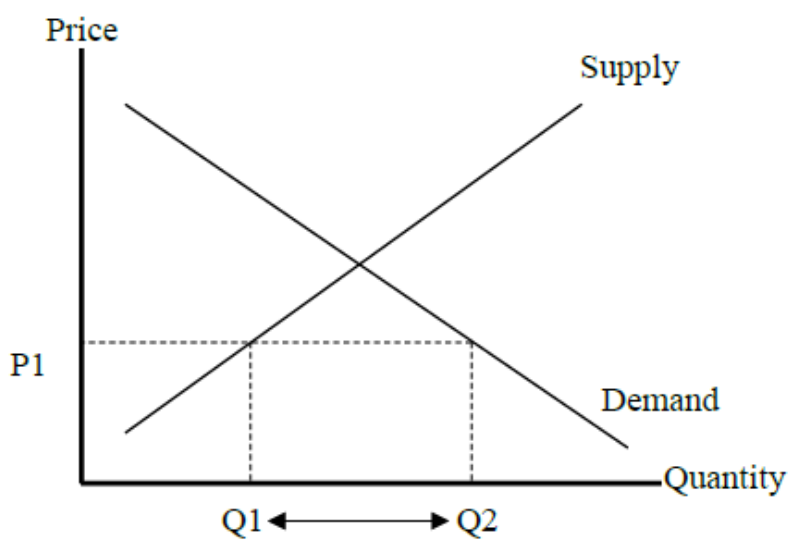

Figure I Shortage

\section{GOVERNMENT REGULATION}

\subsection{Cost Policy}

Despite the availability of adequate medical resources, countries also need to have policies to respond to the costs of treatment. Countries like Canada, Germany or the UK which design their medical system to make sure everybody has insurance to cover at least some amount of medical costs. However, for every country, whether to forgo all medical care costs related to Covid- 19 is still a question. The treatment of Covid19 is pretty costly, from $\$ 1,300$ [5] to $\$ 40,218$ [6], depending on the severity of the disease and the kind of insurance people have. For most people, this is a huge expense. Additionally, people usually have less or even no income during the course of treatment. For people who are uninsured, it is also inhumane for them to stop treatment and wait for deaths. In America, with the passage of the Families First Coronavirus Response Act (FFCRA), most people should not face costs for the Covid- 19 test or associated costs [7]. The policy rules that insurance companies must cover the test costs without cost- sharing. This spares financial pressure for a lot of people while encouraging people taking the test. In this pandemic, a lot of infected people actually have no symptoms at all but still have the ability to infect other people. With more people taking the test and receiving proper quarantine and treatment, the infection rate will be restrained. Even though the policy doesn't have specific requirements for treatment cost, some major insurers have voluntarily waived some or all treatment costs. However, Covid-19 also has a lot of complications during the process, many patients still receive some surprise bills. While people losing their jobs, the uninsured rate will also rise, causing more people to have no insurance at all. This remains a problem to solve. For China, the main policy is to cover all costs. The insurance company will pay for the contracted part, the rest will be covered by the regional government. While this is good for all patients, especially for those who have several 
complications that require special expensive treatment, the total cost is still a huge burden for the government.

\subsection{Restriction Policy}

Because of the pandemic, countries have also initiated some restriction policy. Different countries posed different travel restriction policies: total or partial closures. For residents in the country, there are also policies that keep people indoors or work from home. Even though such travel restrictions cause difficulties for economic development, they are necessary in the case of an epidemic. Long travels with planes and trains means high mobility of people and a closed environment that can increase the infection rate and difficulty of locating infection sources. Even though the travel ban may cause a short- term decrease in economic development, this will make sure the limited medical resources used to the best part. Travelling infection will increase people's demand towards medical resources. However, this is still a huge challenge to countries that rely a lot on tourism. More people will lose jobs and sources of income: hotel staff, restaurants owners, etc. Until early June, the pandemic has lasted for almost four months, most small firms are permanently shut down, including some fancy restaurants. For these owners, once cash flow is cut down, their firms and companies rely on the owners' own savings to maintain. Even though governments offer tax cuts or low- interest bank loans, small firms still have no income but only costs. According to the Washington Post, 20.5 million people in the US lost their jobs in April [8]. High unemployment is happening around the world, which is becoming one of the major problems caused by COVID- 19. Due to lose their jobs, people will cut their spending to increase their precautionary savings. The overall demand shifted to the left like in Figure II. Firms will also prefer safer investment. Economics is slowing down and shrinking. As schools are shutting down and changing to remote learning, poorer families are facing a lot of challenges: limited Internet access, additional spending to purchase computers, losing free lunch, etc. These families usually tend to be low- skilled: waitresses, drivers, workers, the pandemic has already taken at least part of their income. Additional spending makes their lives even harder. All of these are waiting for the governments to be solved.

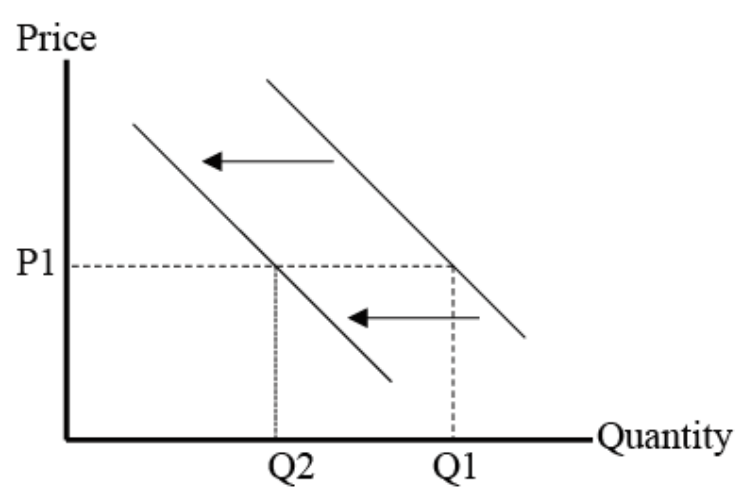

Figure II Demand decreases

\subsection{Technology Tracking}

Because of the high rate of Covid-19 infection, it is critical to suppress chains of transmission. Tracking and tracing technologies are effective tools to fight against Covid-19, but there are risks to civil liberties. If we look at the data separately, some of the data doesn't reveal personal information, but all the data collected and used later may be linked to specific people, as the disease map may show some specific characteristics. Certain countries like China, have all power to access the tracing apps information, which may be the reason they are able to trace possible infected patients quicker than other countries. The GPS record of the phone will memorize all the signals that have close contact with the person, if there is a potential patient, the government or hospitals will be able to locate possible cases due to close contact with the patient. The US also has designed a similar program that voluntary individuals will share useful digital footprints to enable alerts to users who may have contact with infected people. However, this brings up problems with forcibly quarantine and other privacy revealing to the government. Potential hackers can attack the government to obtain this kind of information. Administrative controls are needed to prevent unintended outcome. In the United States, there are already protests that the government is using the pandemic to better control the citizens. To prevent riot, additional police and guards are needed which can bring more cases of coronavirus. The conflict between privacy and monitoring still needs to be solved. For now, big technology firms like Google and Apple are working together with the government to come up with a more friendly solution to protect privacy and have precise tracking. However, this app is quite costly. Most agencies are not funded enough to engage with new kinds of data or innovations [9]. The government may also need to balance the total budget between the cost of health care and the cost of technology, as this is also critical to prevent economic recession. 


\section{CONCLUSION}

We can see that most countries find good ideal policies to control the pandemic. However, different countries meet different problems that prevent the policy to be effective. When we look at a country's health system, it is critical to see how prepared it is. How to encourage additional supply? As we learn more about the pandemic, we are more prepared to face the challenges of the pandemic. We are having a steadier supply of medical resources and more effective cure. Vaccination is also developing. During this hard time, drug industry is one of the few that may have stock prices increase. To encourage the invention vaccination, government usually will publish some beneficiary policies: more research budget, future tax cut policies, etc. When the vaccination is finally developed, it is rational to expect a huge market price increase for the company. However, the profit still depends on the development cost. Additionally, the government will expect the price of the vaccination to be low to make sure everybody has the chance to receive the vaccination. The pandemic gave the world a big hit. Countries and people received a lot of challenges because of the COVID-19. While all the doctors and scientists are doing their best to save us, we got the chance to improve our lifestyles: paying more attention to sanitizing, healthier lifestyles, etc. There will be an end and we will use this chance to improve than suffer.

\section{REFERENCES}

[1] World Health Organizations, 2020. "Coronavirus disease (COVID- 2019) situation reports". DOI: https://www.who.int/emergencies/diseases/novelcoronavirus-2019/situation-reports

[2] The World Bank, "Hospital bed (per 1,000 people). DOI:

https://data.worldbank.org/indicator/SH.MED.BE DS.ZS

[3] The World Bank, "Physicians (per 1,000 people). DOI: https://data.worldbank.org/indicator/SH.MED.PH YS.ZS

[4] Roser, Max, Ritchie, Hannah, Ortiz- Ospina, Esteban, Hasell, Joe (2020). "Statistics and research: Coronavirus (COVID- 19) Cases". DOI: https://ourworldindata.org/covid-cases

[5] Rae, Matthew, Claxton, Gary, Kurani, Nisha, McDermott, Daniel, Cox, Cynthia (2020). "Potential Costs of Coronavirus Treatment for People with Employer Coverage". DOI: https://www.kff.org/health-costs/issuebrief/potential-costs-of-coronavirus-treatment-forpeople-with-employer-coverage/
[6] Levitt, Larry, Schwartz, Karyn, Lopez (2020). "Estimated Cost of Treating the Uninsured Hospitalized with COVID- 19". DOI: https://www.kff.org/coronavirus-covid-19/issuebrief/estimated-cost-of-treating-the-uninsuredhospitalized-with-covid-19/

[7] Fehr, Rachel, Cox, Cynthia, Pollitz, Karen, Tolbert, Jennifer, Cubanski, Juliette, Rudowitz, Robin (2020). "Five things to know about the cost of COVID- 19 Testing and Treatment" Retrieved from. DOI: https://www.kff.org/coronavirus-covid19/issue-brief/five-things-to-know-about-the-costof-covid-19-testing-and-treatment/

[8] Long, Heather, Van Dam, Andrew (2020). "U.S. unemployment rate soars to 14.7 percent, the worst since the Depression era". DOI: https://www.washingtonpost.com/business/202L0/ 05/08/april-2020-jobs-report/

[9] Comstock, Jonah (2020). "At COVID- 19 'paper hearing,' industry, government struggle with balancing privacy, public health". DOI: https://www.mobihealthnews.com/news/covid-19paper-hearing-industry-government-strugglebalancing-privacy-public-health 